Different types of case study are incorporated. These cover, for example, Chernobyl, the tsunamis, Turkish earthquakes, and the Enschede fireworks explosion in The Netherlands. Terrorist incidents in the USA, Israel and London are also well covered. One other disaster I thought might have received some attention was the massive earthquake of 2005 in Pakistan. I also thought that a little more could have been said of the period known as The Troubles in Northern Ireland (1960s-1998) and their impact on the mental health of the Irish nation. On the other hand, I do accept that no one book can cover all major incidents.

Although the reviews of the different topics are very good, I liked the fact that the book has a forward-looking perspective. This is achieved by a critical commentary on the strengths and shortcomings of the studies which the authors have covered. Moreover, they identify important gaps in our knowledge and the challenges facing us if we are to address these. Perhaps some more guidance on ethical issues might also have been useful to prospective researchers.

In summary, however, I commend this book without reservation. It is well written and the editors have achieved a good balance among the chapters. The authors are rigorous in their critical analysis of the research from which the data are derived, and they identify fruitful opportunities for researchers, practitioners and policy makers.

David A. Alexander Director, Aberdeen Centre for Trauma Research, Faculty of Health and Social Care, The Robert Gordon University, Garthdee Road, Aberdeen AB10 7QG, UK. Email: d.a.alexander@rgu.ac.uk

doi: 10.1192/bjp.bp.109.075523

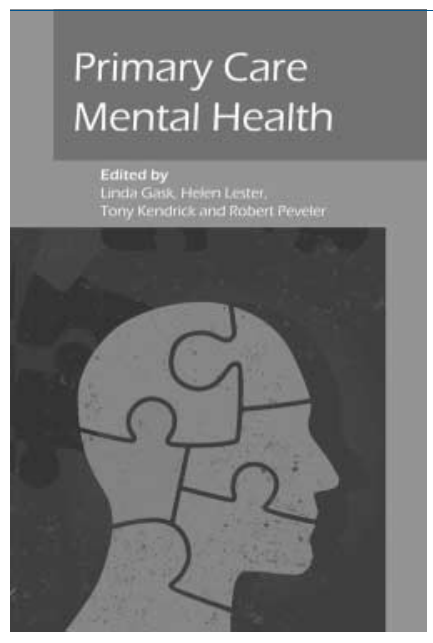

\section{Primary Care Mental Health}

Edited by Linda Gask, Helen Lester, Tony Kendrick \& Robert Peveler. RCPsych Publications. 2009 £35 (hb). 512pp ISBN: 9781904671770

We have here a book of 32 chapters, plus a final epilogue, which is divided into four parts. The first part, containing some of the best chapters in the book, covers the concepts and themes of primary care mental health from an international perspective and the standpoints of policy, sociology, epidemiology and the service user. The second part is the longest, with 16 chapters on the broad diagnoses of particular patient groups. Part 3 revisits policy and practice, looking at the delivery of care and treatment and covering mental health promotion. The final part, 'Reflexive practice', provides a welcome approach to clinical practice, teaching, learning and research and, importantly, addresses the mental health of the practitioner.

There are several excellent chapters in this book which overall makes a first-class attempt to explore the many facets of primary care and its relationship to mental disorder and mental health. Professor Sartorius' contribution to the first section sets the scene by providing an interesting look at the background to the formal definition of primary healthcare, as well as debunking some of the myths of primary care while illuminating its complexities, limitations and ultimate value.

The book is ambitious in its breadth and inevitably focuses much on practice relating to the UK context. It could be seen as two books in one, the second part being the second book. If I have a gripe it is that I would have liked to have seen some of the chapters in the first part developed more to illuminate the exciting conceptual issues raised (for example, the nature of mental health problems and their relation to diagnosis and to population statistics). But that is my preoccupation and I would not let that put the reader off, considering this to be essential reading for trainees and others within the fields of psychiatry, general practice and beyond.

Jed Boardman Consultant and Senior Lecturer in Social Psychiatry, South London and Maudsley NHS Foundation Trust, and Institute of Psychiatry, King's College London, UK. Email: jed.boardman@slam.nhs.uk

doi: 10.1192/bjp.bp.119.075440

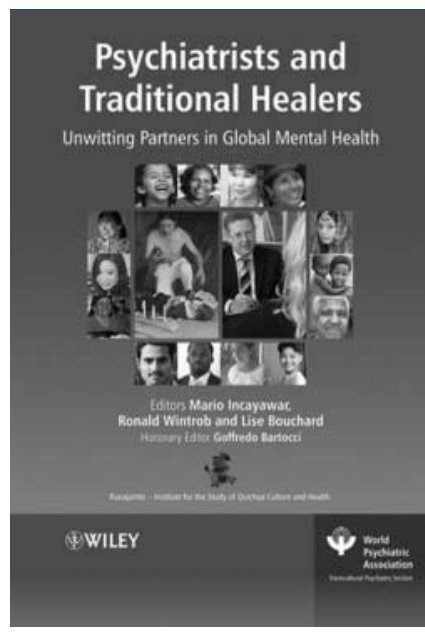

\section{Psychiatrists and Traditional Healers: Unwitting Partners in Global Mental Health}

Edited by Mario Incayawar, Ronald Wintrob, Lise Bouchard \& Goffredo Bartocci. Wiley. 2009. $£ 49.99$ (hb). 294pp ISBN: 9780470516836

Traditional healing is not confined to mental health problems but is offered for virtually all known human ailments. However, it is probably more in psychiatry than in any order branch of medicine that a strong advocacy exists for the integration of traditional healing with Western medicine. It is not unlikely that this reflects, to some extent, the common scepticism about the scientific basis of mental disorders in general.

In examining partnerships between psychiatrists and traditional healers, this excellent book offers the reader a diversity of views to help them form their own opinion about the feasibility of such partnerships. It highlights the challenges of integrating traditional healing with biomedicine, especially given that the nature of the former is so diffuse and its practice often shrouded in secrecy. As the book shows, traditional healers are a diverse group of practitioners ranging from folk herbalists, to diviners and magic witch doctors. The unmet need for mental health services in most low- and middle-income countries, as described by Incayawar, provides the context in which some form of traditional healing sometimes becomes the only available source of help for patients and their families. But the process of integration of traditional healing with modern medicine has to 